\title{
TRADUÇÃO
}

\section{Ensaio VII - Sobre o Raciocínio, Capítulos 1 e 2 (Ensaios sobre as faculdades intelectuais dos seres humanos)}

THOMAS REID

\section{Capítulo 1: Do Raciocínio em geral ${ }^{1}$}

A faculdade do raciocínio é, com justiça, relatada como uma das prerrogativas da natureza humana. Por sua causa, muitas verdades importantes têm sido e poderão ser descobertas e, sem tal capacidade, permaneceriam além do nosso alcance. Ainda assim, ela pode parecer mera muleta para um entendimento limitado. Podemos conceber um entendimento, superior ao humano, ao qual verdades que podemos descobrir apenas pela razão apareceriam intuitivamente. Por tal motivo, embora devamos atribuir juízo ao Todo Poderoso, não atribuímos raciocínio a Ele, pois isso implicaria algum defeito ou limitação em Seu entendimento. Mesmo entre os homens, é irrelevante usar o raciocínio em coisas que são autoevidentes, como alguém que andasse de muletas quando pudesse andar pelas próprias pernas.

Somente pode entender o que é raciocinar aquele que raciocinou e é capaz de refletir sobre essa operação de sua própria mente. Podemos defini-la por sinônimos apenas, como inferir, concluir, entre outros. A noção de raciocínio só pode, portanto,

${ }^{1}$ Tradução: Katyana Martins Weyh, Nilson Rodrigo da Silva e Suellen Dantas Godoi. Revisão: Marcelo do Amaral Penna-Forte. 
entrar na mente por uma única via, a saber, ao refletir sobre a operação de raciocínio em nossas mentes. As noções de premissas e conclusão, de silogismo e de suas partes constituintes, de um entimema, sorites, demonstração, paralogismo, e muitas outras, têm a mesma origem.

A faculdade do raciocínio, sem dúvida, nos é dada pela natureza. Nenhuma arte ou educação pode suprir sua falta. No entanto, tal capacidade pode permanecer adormecida por toda a vida, como a semente de uma planta, a qual, por falta de calor e umidade, jamais germina. Este é, provavelmente, o caso de alguns selvagens.

Embora tal capacidade seja tão somente uma dádiva da natureza, dada provavelmente em diferentes graus a diferentes pessoas, ainda assim ela parece ser obtida pelo hábito, tanto quanto a capacidade de andar ou correr. Não podemos nos lembrar dos primeiros esforços para raciocinarmos, tampouco discernir claramente os de outras pessoas. São muito tênues e precisam ser transmitidos pelo exemplo e reforçados pela autoridade. Aos poucos, adquirem força, sobretudo por meio da imitação e do exercício.

Raciocinar sobre vários assuntos não apenas fortalece a própria faculdade, mas fornece à mente um estoque de potencialidades. Cada cadeia de raciocínio que se torna familiar abre passagem para muitas outras. Remove muitos obstáculos do caminho e facilita e prepara as muitas sendas que poderemos tomar em investigações futuras.

Sempre que pessoas de mesmo poder de raciocínio o aplicam sobre qualquer tema, aquela que mais raciocinou sobre o assunto em questão, ou assunto similar, encontra-se em vantagem sobre a outra, 
como o mecânico que já possui seu conjunto de ferramentas tem vantagem sobre aquele que ainda precisa construí-las, ou mesmo inventá-las.

Em uma cadeia de raciocínio, quando nada é deixado para ser completado pelo leitor ou ouvinte, a evidência de cada passo deve ser imediatamente discernível para qualquer pessoa de entendimento maduro que tenha uma compreensão clara das premissas e da conclusão e que as possa apreciar conjuntamente. Ser capaz de compreender, numa única visada, uma combinação de passos como esse é mais difícil, além de parecer exigir uma habilidade natural superior. É possível, contudo, melhorar bastante com o hábito.

Mas o maior talento em raciocinar é a criação de provas, pelas quais verdades ora distantes das premissas são trazidas à luz. De todos os aspectos do entendimento, tal criação tem o mais alto valor: ela requer visão ampla daquilo que se relaciona com o assunto e perspicácia para discernir as afinidades e relações que podem estar em questão.

Em qualquer criação deve haver algum fim em vista e a sagacidade em descobrir o caminho que conduz a esse fim é, penso eu, o que chamamos de criação. Junto a concepções claras e distintas e mais do que a qualquer outra coisa, creio que nisso consiste aquela superioridade de entendimento que chamamos genialidade.

Em cada cadeia de raciocínio, a evidência da última conclusão não pode ser maior do que a do mais fraco elo da corrente, independente da força dos demais.

Entre os raciocínios, a distinção mais digna de nota é que alguns são prováveis e outros, demonstrativos. 
Em cada passo do raciocínio demonstrativo, a inferência é necessária e percebemos que é impossível que a conclusão não se siga das premissas. No raciocínio provável, a conexão entre as premissas e a conclusão não é necessária, tampouco percebemos ser impossível ocorrer que as primeiras sejam verdadeiras e, em assim sendo, a última ser falsa.

Consequentemente, o raciocínio demonstrativo não tem graus, nem pode uma demonstração ser mais forte que outra, embora, em relação às nossas faculdades, uma possa ser mais fácil de compreender que outra. Cada demonstração dá a mesma força para a conclusão e não deixa possibilidade de ela ser falsa.

Era opinião de todos os antigos, creio, que o raciocínio demonstrativo pode ser aplicado somente a verdades que são necessárias e não àquelas que são contingentes. Nisso, acredito, julgaram certo. A existência de todas as coisas criadas, seus atributos e, consequentemente, as relações resultantes desses atributos, são contingentes. Dependem da vontade e poder d'Aquele que os criou. Essas são questões de fato e não admitem demonstração.

O campo do raciocínio demonstrativo, portanto, são as variadas relações de coisas abstratas, isto é, de coisas que concebemos sem levar em conta sua existência. Dessas coisas, por serem concebidas pela mente e não serem nada além daquilo que são concebidas ser, podemos ter uma compreensão clara e adequada. Suas relações e atributos são necessários e imutáveis. São as coisas às quais pitagóricos e platônicos deram o nome de ideias. Permitam emprestar desses filósofos antigos esse sentido da palavra ideia para, então, concordar com eles no tocante às ideias serem os únicos objetos sobre os quais podemos raciocinar demonstrativamente. 
Mesmo entre nossas ideias, contudo, há muitas que não podem ser desenvolvidas em longas correntes de raciocínio. Embora sejam sempre bem definidas e perfeitamente compreendidas, seus acordos e desacordos são poucos e discernidos imediatamente. Podemos avançar um passo ou dois na formação de uma conclusão sobre tais objetos, mas não podemos ir além disso. Há outras ideias sobre as quais podemos, por meio de uma longa corrente de raciocínios demonstrativos, chegar a conclusões muito remotas e inesperadas.

Os raciocínios que encontrei, passíveis de ser chamados estritamente de demonstrativos, podem, creio, ser reduzidos em duas classes. São eles ou metafísicos ou matemáticos.

No raciocínio metafísico, o processo é sempre curto. A conclusão não está senão a um passo ou dois, raramente mais, do primeiro princípio ou axioma em que se fundamenta, e as diferentes conclusões não dependem uma das outras.

O contrário se dá no raciocínio matemático. Aqui o campo não tem limites. Uma proposição leva a outra, essa a uma terceira, e assim por diante, ilimitadamente.

Em caso disso ser questionado, por que o raciocínio demonstrativo tem tão amplo lugar na matemática, enquanto, em outros temas abstratos, é confinado dentro de limites bem estreitos, concebo que é devido principalmente à natureza da quantidade, o objeto da matemática.

Se questionássemos o porquê de o raciocínio demonstrativo ser tão amplamente difundido na matemática enquanto que, em outros domínios abstratos, ele é confinado em estreitos limites, eu diria que isso é devido, sobretudo, à natureza da quantidade, o objeto da 
matemática.

Com respeito à magnitude, cada quantidade, uma vez que possui magnitude e pode ser dividida em partes sem fim, mantém determinada proporção com qualquer quantidade de seu tipo. As proporções das quantidades são inumeráveis, tal como a metade, um terço, um décimo, o dobro, o triplo.

Todo o alcance dos números é insuficiente para expressar a variedade de proporções. Pois há inúmeras proporções que não podem ser perfeitamente expressas por números, tal como a razão entre o lado e a diagonal de um quadrado, ou entre o perímetro de uma circunferência e seu diâmetro. Dessa variedade infinita de proporções, cada uma pode ser claramente concebida e distintamente expressa, de modo que não há perigo de se tomar uma por outra.

Quantidades extensas, como as linhas, as superfícies e os sólidos, além da variedade de relações que possuem no tocante à magnitude, não têm menos variedade no que concerne à figura. Ademais, cada figura matemática pode ser definida com precisão suficiente para distingui-la de qualquer outra.

Não há nada desse tipo em outros objetos do raciocínio abstrato. Alguns deles têm vários graus, mas não são passíveis de serem medidos, nem podemos lhe atribuir uma proporção para com outros do mesmo tipo. Eles são ou simples ou compostos de poucas partes indivisíveis. Portanto, por assim dizer, levantam poucos pontos. Mas quantidades matemáticas, sendo feitas de partes sem fim, levantam inúmeros pontos e podem ser comparadas de 
inúmeros modos diferentes ${ }^{2}$.

Tem havido tentativas para medir o mérito das ações por meio das razões entre as afecções e os princípios dos quais derivam. Isso talvez possa ilustrar, na forma de analogia, o que de algum modo já é conhecido. Não creio, contudo, que qualquer verdade possa vir a ser descoberta dessa maneira. Há, sem dúvida, graus de benevolência, de amor-próprio e de outras afeç̧ões, mas quando aplicamos proporções a elas, não creio que lidemos com outros significados.

Algumas demonstrações são ditas diretas, outras, indiretas. O primeiro tipo conduz diretamente à conclusão a ser provada. Das indiretas, algumas são ditas demonstrações ad absurdum. Nessas, a proposição contraditória àquela que é provada é demonstrada ser falsa, ou que conduz ao absurdo, do que segue ser sua contraditória isto é, a proposição a ser provada - verdadeira. Tal inferência encontra fundamento em um axioma da Lógica, segundo o qual, de duas proposições contraditórias, se uma for falsa, a outra tem de ser verdadeira.

Outro tipo de demonstração indireta enumera todas as suposições contrárias à proposição a ser provada e, em seguida, demonstra que são todas são falsas, à exceção da que é objeto da prova, do que segue ser verdadeira a suposição excetuada. Assim, uma linha é provada ser igual a outra, ao se provar, antes, que ela não pode ser maior e, depois, que não pode ser menor. Isso por que ela tem de ser ou maior, ou menor, ou igual à outra linha e, tendo sido

${ }^{2}$ No original, há um jogo de palavras: “(...) therefore, if we may be allowed the expression, can touch only in few points. But mathematical quantities being made up of parts without number, can touch in innumerable points". [NdT] 
demonstrado que duas dessas suposições são falsas, a terceira tem de ser verdadeira.

Todos esses tipos de demonstração são usados na matemática e, possivelmente, também alguns outros. Eles têm a mesma força. A demonstração direta é preferida onde puder ser realizada, pela simples razão, tal como vejo, de ser o caminho mais curto para a conclusão. A natureza da evidência, e sua força, é a mesma em todas. Ocorre apenas que somos conduzidos a ela por caminhos diferentes. 


\section{Capítulo 2: Se a moralidade é suscetível de demonstração ${ }^{1}$}

O que tem sido dito acerca do raciocínio demonstrativo pode nos ajudar a considerar uma opinião de Locke, apresentada em diversas partes de seu Ensaio, a saber, "que a moralidade é suscetível de demonstração tal como a matemática”.

No Livro III, Capítulo XI, Seção 16, tendo observado que, quanto aos modos mistos, especialmente os pertencentes à moralidade, sendo combinações de ideias que a mente reúne mediante sua própria escolha, o significado de seus nomes pode ser perfeita e exatamente definido, ele acrescenta:

Com base nisso é que me inclino a pensar que a moralidade é suscetível de demonstração tal como a matemática. Uma vez que a essência real e exata das coisas que as palavras morais significam pode ser perfeitamente conhecida, seguramente pode ser descoberta a congruência ou incongruência das próprias coisas, e nisso consiste o conhecimento perfeito. Nem deixo objetarem que os nomes das substâncias, bem como dos modos - dos quais resulta a obscuridade -, são muito usados na moralidade. Pois, quanto às substâncias, quando referidas nos discursos morais, suas diversas naturezas são mais supostas do que propriamente investigadas. Por exemplo, quando dizemos que as pessoas estão sujeitas à lei, por "pessoa" não dizemos nada além do que uma criatura corpórea e racional. Não é considerada, em absoluto, qual seria a essência real dessa criatura, ou outras de suas qualidades.

Novamente, no Livro IV, Capítulo III, Seção 18:

A ideia de um Ser Supremo, infinito em poder, bondade e

1 Tradução: Marcelo do Amaral Penna-Forte e Josieli Aparecida Opalchuka. 
sabedoria, cuja obra somos nós, e do qual dependemos, bem como a ideia de nós mesmos, enquanto criaturas racionais e dotadas de entendimento, sendo tão claras para nós, concederiam, suponho, se devidamente consideradas e investigadas, os fundamentos do nosso dever e regras para ação de modo a colocar a moralidade entre as ciências suscetíveis de demonstração. A relação de outros modos seguramente pode ser percebida, tal como o são as de número e de extensão. Além disso, não posso ver por que não seriam passíveis de demonstração, caso fossem encontrados métodos capazes de examinar ou determinar sua concordância ou discordância.

Em seguida, apresenta, como exemplos, duas proposições na condição de proposições morais das quais podemos estar tão certos quanto de quaisquer outras na matemática e considera, de passagem, o que poderia ter dado vantagem às ideias de quantidade e tê-las feito serem pensadas como mais propícias à certeza e demonstração.

Novamente, no Capítulo XII do mesmo livro, Seções 7 e 8:

Isto, creio, posso dizer: se outras ideias que sejam essências tanto reais como nominais de suas variadas espécies fossem investigadas do modo familiar ao matemático, levariam nosso pensamento, com maior evidência e maior clareza, mais além do que podemos imaginar. Isso me tornou confiante em apresentar a conjectura que sugeri no Capítulo III - a saber, que a moralidade é suscetível de demonstração tal como a matemática.

Essas passagens fazem parecer que tal opinião não é mero pensamento passageiro, mas algo que revolveu sua mente em diferentes ocasiões. Ele oferece suas razões, ilustra-a, e examina extensamente as causas que levaram as pessoas a pensar a matemática como mais suscetível de demonstração do que os 
princípios da moral.

Alguns de seus eruditos correspondentes, particularmente seu amigo Sr. Molyneux, incitou-lhe continuamente a compor um sistema moral condizente com as ideias apresentadas em seu Ensaio. Em suas respostas a tais solicitações, ele tão somente alegou ter outras ocupações, sem sugerir qualquer mudança de opinião ou dificuldades maiores na execução daquilo que era pleiteado.

A razão que ele oferece para sua opinião é engenhosa e sua consideração para com a virtude - a prerrogativa maior da espécie humana - o fez preferir uma opinião que parecesse favorável à virtude e possuísse um embasamento sólido na razão.

Não precisamos, no entanto, temer que as vantagens da virtude sejam abaladas por um exame livre e honesto dessa questão - ou de qualquer outra, por sinal -, pois os interesses da virtude e da verdade nunca poderão ser dispostos em oposição. A escuridão e o erro podem proteger o vício, mas nunca serão favoráveis à virtude.

Os filósofos que pensam que nossas determinações morais não são juízos reais - que o certo e o errado na conduta humana são apenas sentimentos ou sensações das pessoas ao contemplarem as ações - devem rejeitar a opinião de Locke sem ao menos examiná-la. Isso porque, caso os princípios da moral não sejam questão de juízo, mas, sim, de sentimentos apenas, não poderão ser demonstrados. Tampouco poderão ser oferecidas suas razões, exceto que as pessoas são constituídas pelo Autor de seus seres de modo a contemplar com prazer as ações que chamamos virtuosas e com desgosto as que chamamos de vícios.

Não é de esperar, portanto, que filósofos dessa estirpe pensem 
que a opinião de Locke seja digna e exame, uma vez que se encontra fundamentada naquilo que consideram ser uma falsa hipótese. Mas se nossas determinações morais são juízos reais e, como quaisquer outros juízos, são verdadeiras ou falsas, não é algo sem importância entender sobre que tipo de evidência tais juízos repousam.

$\mathrm{O}$ argumento oferecido por Locke para mostrar que a moralidade é suscetível de demonstração é este: "uma vez que a essência real e exata das coisas que as palavras morais significam pode ser perfeitamente conhecida, seguramente pode ser descoberta a congruência ou incongruência das próprias coisas, e nisso consiste o conhecimento perfeito".

É verdade que o domínio da demonstração são as diversas relações entre as coisas, pensadas abstratamente e das quais podemos ter concepções adequadas e perfeitas. Locke, tomando como desse tipo todas as coisas significadas pelas palavras morais, concluiu que a moralidade é suscetível de demonstração tal como a matemática.

Reconheço que os nomes das virtudes e dos vícios, dos direitos e dos deveres, da liberdade e da propriedade, referem-se a coisas abstratas, que podem ser exatamente definidas ou, ao menos, concebidas tão adequada e distintamente quanto as quantidades matemáticas. Segue disso, com efeito, que suas relações mútuas podem ser percebidas tão certa e claramente quanto as verdades matemáticas.

Disso, Locke oferece dois exemplos pertinentes. O primeiro "onde não há propriedade, não há injustiça”, diz ele, "é uma proposição tão certa quanto qualquer proposição em Euclides”. 
Quando a injustiça vem a ser definida como violação de propriedade, trata-se de uma verdade necessária que não possa haver injustiça onde não haja propriedade, do mesmo modo como não se pode tirar de alguém aquilo que ele não possui.

O segundo exemplo é "nenhum governo permite liberdade absoluta”. Eis uma verdade não menos certa ou necessária.

Tais verdades abstratas, eu as chamaria metafísicas em vez de morais. Damos o nome de matemáticas às verdades que expressam as relações de quantidade consideradas abstratamente. Quaisquer outras verdades abstratas podem ser chamadas metafísicas. Mas, se as mencionadas por Locke devem ser chamadas de verdades morais, concordo com ele em que haja muitas delas que sejam necessariamente verdadeiras e que têm toda a evidência que as verdades matemáticas poderiam ter.

Mas algo que eu disse anteriormente deve ser lembrado aqui: as relações entre as coisas abstratas que são percebidas por nós são poucas - exceto relações entre quantidades matemáticas - e, no mais das vezes, são imediatamente discernidas, não precisando ser encontradas mediante a cadeia de raciocínios que chamamos demonstração. Assemelham-se, assim, mais aos axiomas matemáticos que às proposições matemáticas.

Isso ocorre nas duas proposições dadas por Locke como exemplo. A primeira segue imediatamente da definição de injustiça. A segunda, da definição de governo. Sua evidência é mais propriamente dita intuitiva que demonstrativa. Além do mais, pelas razões apresentadas no capítulo anterior, penso que isso, ou algo próximo a isso, vale para todas as verdades abstratas que não sejam matemáticas. 
As proposições que creio ser devidamente chamadas de morais são aquelas que dizem que certa obrigação moral é ou não é imputável a um ou mais indivíduos. O raciocínio de Locke não se aplica a tais proposições, pois os indivíduos das proposições não são coisas cuja essência real pode ser perfeitamente conhecida. Deus os fez, suas obrigações resultam da constituição que Deus lhes deu e das circunstâncias em que Ele os colocou. Que este indivíduo tem tal ou qual constituição e é colocado em tais e tais circunstâncias não é uma verdade abstrata e necessária, mas contingente. É uma questão de fato e, portanto, não é suscetível de evidência demonstrativa, característica apenas das verdades necessárias.

A evidência que cada um possui de sua própria existência, embora seja irresistível, não é demonstrativa. O mesmo vale para a evidência de que cada pessoa é um agente moral e possui obrigações morais. Nem se trata de evidência demonstrativa a que temos da existência de outras pessoas, tampouco a que temos de serem elas dotadas de faculdades que as tornam agentes morais e responsáveis.

Se as pessoas não tivessem a faculdade dada por Deus de perceber como certas ou erradas algumas coisas em suas condutas, e de perceber suas obrigações de fazerem o que é certo e não fazerem o que é errado, não seriam seres morais e responsáveis.

Se as pessoas são dotadas de tal faculdade, a correção de algumas ações e o erro de outras lhes serão imediatamente discerníveis. Deve haver na moral, portanto, como em outras ciências, princípios primeiros que não derivam da evidência de quaisquer princípios antecedentes, mas que podem ser ditos conhecidos intuitivamente.

As verdades morais, por conseguinte, podem ser divididas em 
duas classes: aquelas que são autoevidentes para todos aqueles cujo entendimento e faculdade moral estejam complemente formados, e aquelas que são deduzidas por raciocínio a partir das que são autoevidentes. Se as primeiras não puderem ser discernidas sem o raciocínio, as outras nunca poderão sê-lo por qualquer raciocínio.

Se alguém pudesse sinceramente dizer que não está ciente de qualquer obrigação de considerar sua própria felicidade presente e futura; de manter suas promessas, de obedecer a Deus, seu criador; e de não ferir ninguém, não sei qual raciocínio - seja provável ou demonstrativo - eu poderia usar para convencê-lo de qualquer dever moral. Assim como não se pode raciocinar em matemática com alguém que negue os axiomas, também não se pode raciocinar na moralidade com quem nega os princípios primeiros da moral. Aquele que não percebe, à luz de sua própria mente, que algumas ações são corretas e outras são erradas é tão incapaz de raciocinar sobre a moral como um cego o é sobre as cores. Tal pessoa, se é que tenha existido, não seria um agente moral e não seria capaz de quaisquer obrigações morais.

Alguns princípios da moral devem ser imediatamente conhecidos, caso contrário, não temos nenhuma base sobre a qual outros princípios possam se apoiar, não há axiomas a partir dos quais podemos raciocinar.

Todos sabem, seguramente, que deveriam fazer, em circunstâncias semelhantes, aquilo que aprovam que outros façam e que não deveriam fazer o que condenam. Todos sabem que devem sinceramente fazer o melhor que podem para saber qual é seu dever. Para todos que têm consciência, tais coisas são autoevidentes. Elas são imediatamente ditadas pela nossa faculdade moral, que é parte 
da constituição humana, e cada um se condena, quer queira ou não, sempre que age sabidamente em contradição com eles. A evidência desses princípios básicos da moral, e de outros que venham a ser nomeados, portanto, parecem a mim ser intuitiva em vez de demonstrativa.

Aquele que age de acordo com os ditames de sua consciência e se esforça para estar correto quanto ao seu dever é uma pessoa perfeita no que concerne à moral e, por isso, não merece reprovação alguma, quaisquer que sejam as imperfeições ou erros de seu entendimento. Aquele que age sabidamente em desacordo com eles é consciente de sua culpa, e condena a si mesmo. Todo agir que se mostre evidentemente conforme as regras básicas de moral é, evidentemente, o seu dever. Não é necessário raciocínio algum para convencê-lo de que é assim.

Desse modo, penso que todos de entendimento comum sabem, com segurança e sem raciocínio, quais os fins últimos que deveriam perseguir e que raciocinar só é necessário para descobrir os melhores meios para atingi-los - no que diz respeito a isso, uma pessoa boa pode, com efeito, muitas vezes estar em dúvida.

Assim, um magistrado sabe que é seu dever promover o bem da comunidade que lhe confiou a autoridade. Seria um insulto oferecerse para prová-lo pelo raciocínio. Mas se ele deve conduzir seu ofício deste ou daquele outro modo para melhor servir a esse fim, ele pode vacilar. Muito raramente, creio, ele obterá uma evidência demonstrativa nesses casos. Sua consciência determina o fim que ele deve perseguir e ele possui evidência intuitiva de que tal fim é bom. No entanto, é a prudência que deve determinar os meios para atingir esse fim e a prudência quase nunca pode usar o raciocínio 
demonstrativo, mas, sim, basear-se no que parece mais provável.

Penso que isso vale para todo o tipo de dever que temos para com Deus ou com nossos semelhantes - isto é, que a obrigação às mais gerais regras do dever é autoevidente; que a aplicação dessas regras a ações particulares não é, na maioria dos casos, menos evidente; e que, quando não é evidente, mas exige raciocínio, muito raramente se trata do raciocínio demonstrativo, mas de tipo provável. Às vezes depende do temperamento, dos talentos, e das circunstâncias em torno daquele que age. Às vezes, das circunstâncias e do caráter de outros; às vezes de ambos. Trata-se, enfim, de coisas que não admitem demonstração.

Todos são obrigados a empregar no melhor dos propósitos seus talentos dados por Deus, mas, se por acidentes que não poderiam prever, ou por ignorância incontornável, tais talentos não sejam tão bem empregados como poderiam ser, isso lhes será imputado pelo Justo Juiz.

É comum e justo observar que as pessoas virtuosas jogam um jogo mais convicto, a fim de obter seus fins, do que as mundanas. Não é, no entanto, porque raciocinam melhor sobre os meios de alcançar seu fim - afinal, os filhos deste mundo são muitas vezes mais astutos no trato entre si do que os filhos da luz. Mas a razão da observação é que os erros involuntários, os acidentes imprevistos e a sempre presente ignorância, que afetam profundamente todos os problemas deste mundo, não têm nenhum efeito sobre a virtude ou sua recompensa.

Nas ocorrências comuns da vida, uma pessoa íntegra que tenha exercido sua faculdade moral para julgar o que é certo e o que é errado vê seu dever sem raciocinar, tal como vê seu caminho. Os 
casos que exigem raciocínio são poucos em comparação com aqueles que dele prescindem, e uma pessoa pode ser muito honesta e virtuosa sem ser capaz de raciocinar e sem saber o que quer dizer uma demonstração.

A faculdade de raciocinar, naqueles que a possuem, pode ser mal utilizada na moral como em outras questões. $\mathrm{O}$ raciocínio será extremamente útil para quem usá-lo com um coração reto e um olho focado na busca de qual é seu dever. Mas quando for usado para justificar simplesmente aquilo que alguém tem uma forte inclinação a fazer, só servirá para enganar a si mesmo e aos outros. Quando alguém tem o poder de raciocinar, suas paixões raciocinarão, e são estas os sofistas mais ardilosos que viremos a conhecer.

Se as regras da virtude fossem deixadas a ser descobertas pelo raciocínio demonstrativo, ou pelo raciocínio de qualquer espécie, isso seria uma coisa lamentável para a grande maioria das pessoas, que não têm os meios para desenvolver seu poder de raciocínio. A virtude é um cometimento de cada indivíduo. Seus primeiros princípios estão escritos em seus corações em letras tão legíveis, que ninguém pode fingir ignorá-los ou a sua obrigação de praticá-los.

Algum conhecimento do dever e da obrigação moral é necessário para todos. Sem isso, não poderíamos ser criaturas morais e responsáveis, ou capazes de nos tornarmos membros da sociedade civil. Por conseguinte, pode-se presumir que a Natureza colocou esse conhecimento ao alcance de todos. O raciocínio e demostração são armas que a maior parte da humanidade nunca foi capaz de dominar. O conhecimento que é necessário a todos deve poder ser alcançado por todos. Vemos que isso é assim em tudo o que diz respeito à vida natural dos seres humanos. 
Por conseguinte, é de esperar, pela analogia da natureza, que tal conhecimento da moral, uma vez necessário a todos, deve ser obtido por meios mais adequados às habilidades comuns a todos os seres humanos do que o é o raciocínio demonstrativo.

Isso, entendo, é de fato o caso. Quando as faculdades estão maduras nas pessoas, os primeiros princípios da moral, em que podem ser resolvidos todos raciocínios morais, são percebidos de forma intuitiva e de modo mais análogo às percepções dos sentidos do que às conclusões do raciocínio demonstrativo.

Concordo com Locke que as proposições que expressem as congruências e incongruências de coisas abstratas que venham a ser designadas por palavras morais podem ter a mesma evidência das verdades matemáticas. Mas isso não é peculiar às coisas que as palavras morais significam. É comum a qualquer espécie de proposições abstratas. Por exemplo, "você não pode tirar de alguém aquilo que ele não possui" ou "ninguém pode ser perfeitamente livre e forçado ao mesmo tempo". Creio que ninguém chamaria tais proposições de verdades morais, mas são verdades necessárias e são tão evidentes quanto qualquer outra na matemática. De fato, elas estão muito próximas das que Locke dá como exemplos de proposições morais suscetíveis de demonstração. De tais proposições abstratas, penso ser mais propriamente dito que possuem a evidência de axiomas matemáticos do que serem passíveis de demonstração.

Há proposições de outro tipo, que merecem independentemente o nome de proposições morais. Elas afirmam que determinadas ações são o dever de pessoas que existem efetivamente. Elas não são proposições abstratas e, portanto, o raciocínio de Locke não se aplica a elas. A verdade de todas essas 
proposições depende da constituição e das circunstâncias das pessoas a quem são aplicadas.

De tais proposições, há algumas que são autoevidentes a todos que têm consciência. Tais são os princípios a partir dos quais todo raciocínio moral deve ser conduzido. Eles podem ser chamados de os axiomas da moral. Mas o nosso raciocínio a partir desses axiomas para qualquer dever que não seja autoevidente quase nunca pode ser demonstrativo. Ainda assim, isso não causa qualquer prejuízo para a causa da virtude. Primeiro, porque agir contra o que parece mais provável em questão de dever é uma transgressão tão real contra os primeiros princípios da moralidade quanto agir contra demonstrações. Segundo, porque aquele que tem apenas um talento para raciocinar, mas dele faz bom uso, será aceito do mesmo modo como o será aquele a quem Deus deu dez. 